Finisterra, XXXV, 70, 2000, pp. 41-55

\title{
A CIRCULAÇÃo do AR NA PENÍNSULA DE TRÓIA E NA COSTA DA GALÉ
}

\author{
Carlos Silva Neto 1
}

\begin{abstract}
Resumo - O litoral ocidental português caracteriza-se, durante o Verão, por uma dominância, muito clara, dos rumos de ventos Norte e Noroeste. Devido à influência da Serra da Arrábida, a Nortada sofre um desvio para W, SW, ou mesmo S, na Península de Tróia, onde se verifica uma elevada frequência dos rumos do vento entre $\mathrm{W}$ e $\mathrm{S}$ durante os meses de Verão. Este desvio é muito mais frequente e nítido durante a noite do que durante o dia. Durante o dia, a Nortada forte é canalizada pela depressão entre o morro de Palmela e a serra do Louro e, com frequência, incide na ponta Norte de Tróia e penetra por toda a Península de Tróia com rumos entre NNE e NNW. Durante a noite, a velocidade do vento N e NW é, em regra, menor, e os ventos com rumos entre $\mathrm{W}$ e $\mathrm{S}$, resultantes do desvio provocado pela Serra da Arrábida/Cabo Espichel, fazem-se sentir em toda a Península de Tróia, a Norte do Carvalhal.

Os rumos do vento entre $\mathrm{W}$ e $\mathrm{S}$, frequentes durante a noite na Península de Tróia, são intensificados pela diferença de temperatura entre o oceano e as águas mais quentes do estuário.

Palavras-chave: Brisa, Estuário do Sado, deflecção do vento, deformação das árvores.

Abstract - Air flow over the Tróia Peninsula and the Costa da Galé In the summer, the Portuguese western coast is characterised by an evident dominance of north and northwest wind directions. Due the influence of the Arrábida mountain, the north wind suffers a deflection and blows from the west, southwest or even south over the Tróia Peninsula, where in the summer months there is a high frequency of wind directions between west and south. This deflection is much more frequent and better marked at night than at daylight. At daylight the strong north wind is channelled through a valley between Palmela hill and the Louro mountain and frequently blows over the Tróia Peninsula, in directions between north-northeast and north-northwest. At night, north and northwest wind speeds are generally lower and west and south winds blow all over the Tróia Peninsula towards Carvalhal, as result of the deflection caused by the Arrábida and Cabo Espichel.

The wind directions between west and south, frequent at night on the Tróia Peninsula, are also intensified by the difference of temperature between the cool ocean and the warm water of the estuary.
\end{abstract}

Key words: Sea breeze, Sado Estuary, wind deflection, wind-shaped trees.

\footnotetext{
1 Professor auxiliar de Geografia da Faculdade de Letras da Universidade de Lisboa. Investigador do Centro de Botânica Aplicada à Agricultura do Instituto Superior de Agronomia. Email: netocarlos@clix.pt
} 


\section{INTRODUÇÃO}

O estuário do Sado e da Costa a Galé caracterizam-se pela predominância de ventos de noroeste e norte, especialmente durante o Verão (Fig. 1); no entanto o regime dos ventos está muito dependente da localização das estações de observação. Assim, observamos que, em Alcácer do Sal (estação situada no vale do Sado), em Janeiro o rumo dominante do vento é de Sudeste, localmente canalizado pelo vale do rio Sado (Fig. 1). Ainda durante o mês de Janeiro, os rumos do vento Norte e NW são dominantes em Águas de Moura e Setúbal, enquanto em Sesimbra/Maçã se verifica um domínio dos rumos de SW e NE. No mês de Julho (período 1953/70) verifica-se uma nítida dominância dos rumos Norte e NW em todas as estações (Fig. 1). Em Alcácer do Sal, o rumo Oeste está bem representado no mês de Julho, devido ao efeito combinado da canalização promovida pelo vale do Sado e a influência da Serra da Arrábida que, com frequência, promove um desvio dos ventos de NW para rumos compreendidos entre Oeste e Sul (Alcoforado, 1994; Barros e BORREGO, 1994).

Quase todas as estações meteorológicas do litoral português apresentam, durante os meses de Verão, uma dominância muito clara dos ventos de Norte e NW que, com frequência, alcançam velocidades elevadas durante a tarde (Nortada) (AlCOFORADO, 1984). A Serra da Arrábida condiciona muito a circulação do ar no sector terminal do estuário do Sado, principalmente na Península de Tróia e na Costa da Galé. Os ventos de Norte e NW sofrem, com frequência, um desvio para W, SW ou mesmo S. Este desvio do vento, frequente nos meses do Verão, vai diminuir o número de registos de ventos do quadrante Norte em toda a Península de Tróia, assim como no sector setentrional da Costa da Galé, e aumenta a frequência dos rumos de vento entre Oeste e Sul.

Este fenómeno tem consequência ao nível das temperaturas superficiais da água do mar e também na formação de nevoeiros litorais durante o Verão (DAVEAu et al., 1985). A Nortada que, durante o Verão afecta a costa ocidental portuguesa, explica a formação de uma corrente de deriva litoral Norte-Sul e as temperaturas da água do mar são particularmente baixas (FERREIRA, 1984). A Península de Setúbal interrompe esta corrente de deriva litoral Norte-Sul (CARvalho e Barceló, 1966) e cria uma situação de abrigo em todo o sector da Península de Tróia e Costa da Galé (até à Praia do Carvalhal) que, assim, apresenta temperaturas da água do mar superiores às que caracterizam, em média, a costa ocidental durante o Verão.

A importância do rumo do vento nas correntes de deriva litoral e na formação de nevoeiros de advecção estivais justificou uma análise mais detalhada da forma como circula o ar no sector terminal do estuário do Sado, em particular na Península de Tróia. 

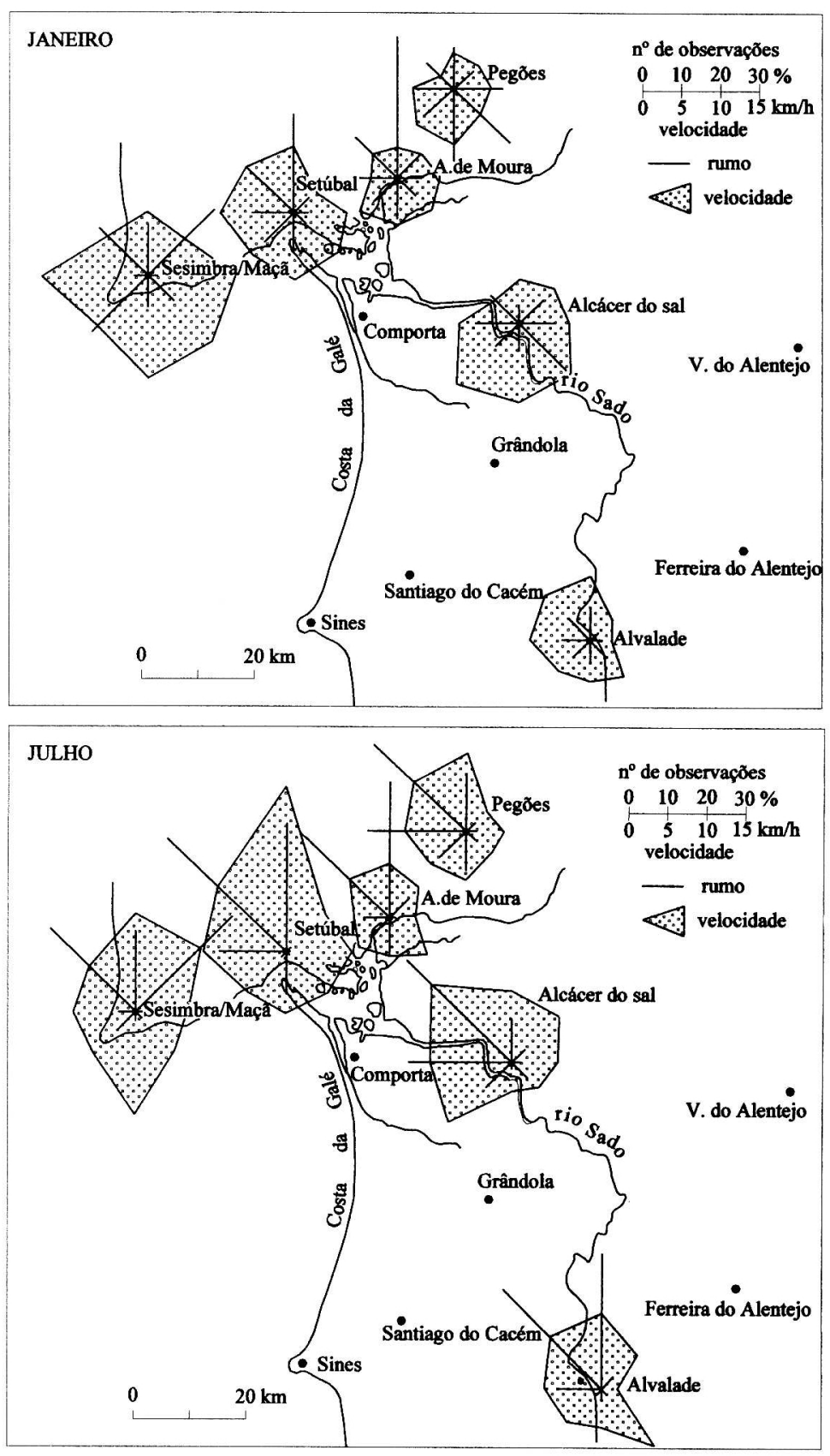

Fig. 1 - Regime e velocidade dos ventos em diversas estações meteorológicas na Península de Setúbal e bacia hidrográfica do rio Sado, Sesimbra/Maçã (1953/70), Pegões (1953/70), Águas de Moura (1953/70), restantes estações (1941/70).

Fig. 1 - Wind direction (rumo) and speed (velocidade) in several meteorological stations. 


\section{TÉCNICAS DE ANÁLISE}

Para realizar este estudo, não foi possível utilizar os dados fornecidos pelas estações do I.M., pois este organismo não possui registos da velocidade e rumo dos vento no litoral, desde a ponta da Península de Tróia até Sines. Assim, utilizaram-se os registos do rumo e da velocidade dos ventos de uma estação privada (estação da Comporta/Santa Mónica), situada na Praia da Comporta, na crista da duna primária. Trata-se da crista mais alta da duna primária e não apresenta obstáculos próximos que possam influenciar a circulação do ar. Com base nos registos gráficos do anemógrafo foi possível apurar o rumo e velocidade do vento para um conjunto de 3 anos (1992, 1993 e 1994). Durante os referidos anos, foram analisados os rumos e a velocidade dos ventos para os meses de Verão (Junho, Julho, Agosto e Setembro). Os registos foram efectuados com intervalos de uma hora, 24 horas por dia, o que forneceu um total de 5813 registos. Os rumos dominantes do vento, com mais de 500 observações, são: SW, 677 registos (12\%); W, 500 registos (9\%); N, 924 registos (16\%); NW, 686 registos (12\%) e NNW, 555 registos (10\%).

A análise da circulação do vento no estuário do Sado foi, também, efectuada a partir da deformação das árvores e de medições itinerantes da velocidade e rumo do vento com um anemómetro e uma bússola. No que respeita à deformação das árvores, foram utilizados indivíduos de Pinus pinaster (pinheiro-bravo) e Pinus pinea (pinheiro-manso), espécies florestais dominantes nas dunas litorais da Península de Tróia e da Costa da Galé. Considerou-se apenas a deformação dos indivíduos relativamente isolados, afastados de obstáculos naturais ou artificiais capazes de alterar localmente o fluxo do ar, e que ocupam as cristas das ondulações dunares.

Para as medições itinerantes da velocidade do vento, foi utilizado um anemómetro manual que permite o registo da rajada máxima e da velocidade média do vento durante um determinado período de tempo (neste caso foram utilizados períodos de 5 minutos). O rumo do vento foi observado com uma bússola, que permite leituras precisas até um grau.

\section{APRESENTAÇÃO E DISCUSSÃO DOS RESULTADOS}

\section{Rumos horários do vento na Comporta de Junho a Setembro}

Foi analisada a distribuição horária de dois somatórios de rumos de vento, respectivamente SW, WSW e SSW, que representam $22 \%$ do total de observações registadas na estação da Comporta, e o conjunto dos rumos NNE, $\mathrm{N}$, e NNW, com 30\%. Estes dois conjuntos correspondem apenas a 37\% dos 16 rumos registados na estação da Comporta, mas ocorreram em $51 \%$ dos casos. Assim, os dois conjuntos de rumos considerados são os mais frequentes na estação da Comporta durante o Verão. A escolha destes dois conjuntos de rumos (SW, WSW, SSW e NNE, N, NNW) baseia-se, também, no facto de se 
verificar uma alternância muito nítida na sua ocorrência entre o dia e a noite. Quando se analisa a variação diária da percentagem de cada um dos referidos conjuntos de rumos relativamente ao total de registos horários de todos os rumos, verifica-se uma dominância dos rumos SW a SSW sobre os de NNE a NNW entre as 20 horas ${ }^{2}$ e as 4 horas (Fig. 2). Entre as 23 e as 24 horas, os ventos de SW a SSW correspondem a $36 \%$ do total de registos, enquanto os rumos NNE a NNW representam apenas $16 \%$ (Fig. 2).

Durante o dia os rumos NNE a NNW são dominantes das 10 às 11 horas (41\% do total de registos).

Os rumos SW a SSW são pouco frequentes durante o dia e registam a percentagem mais baixa das 12 às 13 horas, com apenas $6 \%$ dos registos durante essa hora (Fig. 2).

Durante as noites de Verão, as temperaturas superficiais da água do estuário do Sado são superiores às do oceano, originando-se um vento proveniente do mar em direcção ao estuário, segundo rumos que poderão ir desde Oeste até Sul. Esta diferença de temperaturas entre as águas oceânicas e estuarinas ficou registada, por exemplo, numa imagem de satélite (NOAA, canal 4 infra-vermelho térmico), de 17 de Agosto de 1992 às 3:48 h. Pode observar-se que a temperatura superficial das águas oceânicas é mais baixa do que a temperatura das águas do estuário do Sado. Esta diferença de temperaturas explica o fluxo de ar do oceano em direcção ao interior do estuário do Sado, registado na estação da Comporta/Santa Mónica, em que o vento sopra de SW entre as 21 horas e as 24 horas e de Oeste entre as $0 \mathrm{~h}$ e as $11 \mathrm{~h}$. As diferenças térmicas da superfície das águas, que caracterizam as águas oceânicas relativamente às águas do estuário devem-se aos seguintes factores:

a) Maior espessura da massa de água oceânica. No estuário, desenvolvem-se extensas plataformas de maré (plataformas lodosas e sapais), nas quais, durante a maré alta, a profundidade de água é fraca (entre 1 e $3 \mathrm{~m}$ ).

b) Maior agitação das águas oceânicas relativamente às águas estuarinas. No oceano, a água superficial é substituída por água mais profunda, mais fria. No interior do estuário este arrefecimento superficial das águas é muito menos importante.

c) Quando o período de emersão coincide com as horas de maior calor, durante o Verão, as plataformas de maré, assim como os sapais, registam um aquecimento importante. Quando a água do estuário invade as plataformas de maré aquecidas verifica-se o aumento da sua temperatura. Quem se desloca nestas plataformas lodosas verifica que, durante o Verão, a água que as cobre se encontra tépida em contraste com a água mais fria do litoral oceânico.

2 A hora utilizada refere-se ao TUC (tempo universal coordenado). 

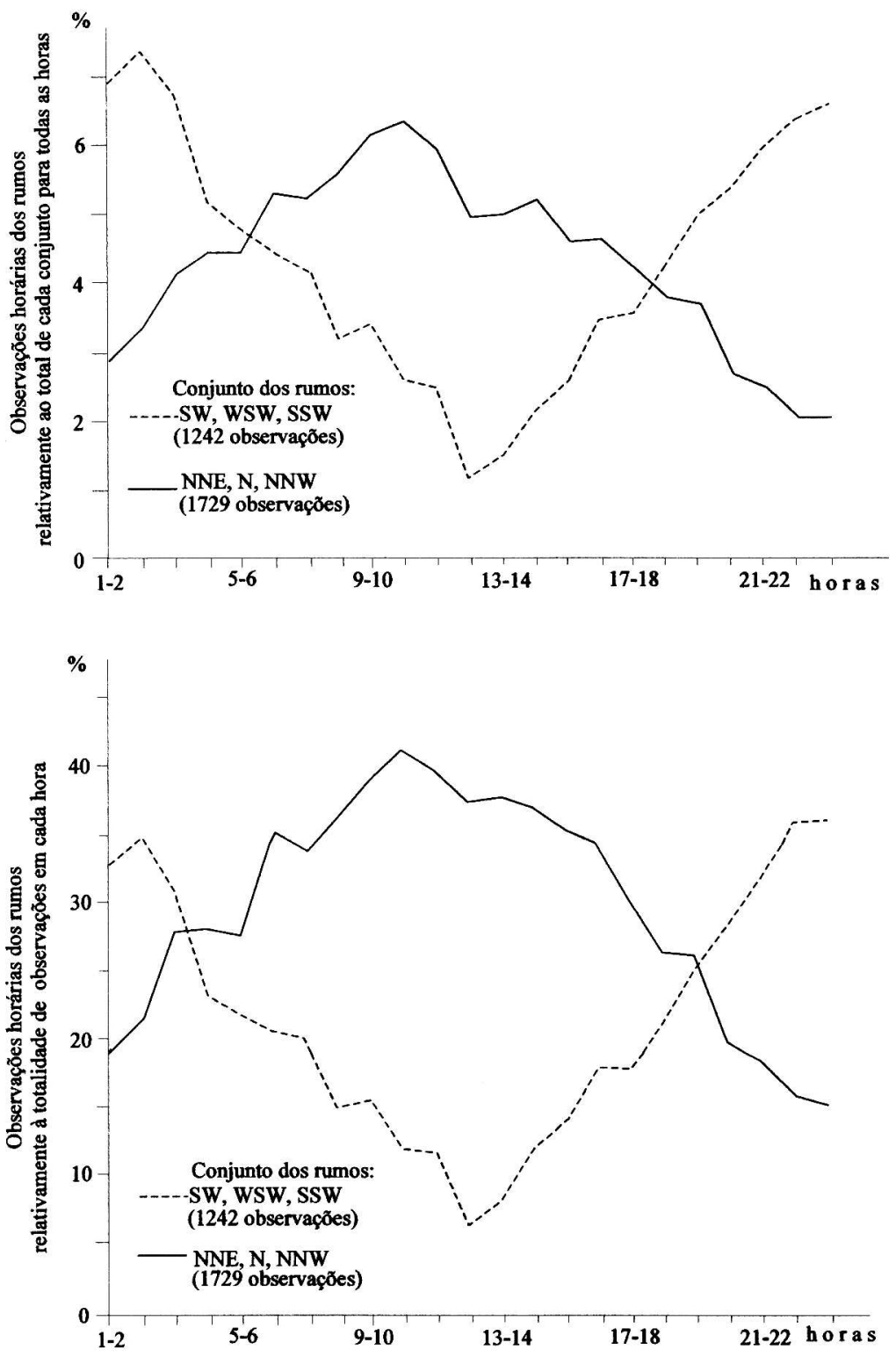

Fig. 2 - Evolução diária do rumo do vento em Comporta/Santa Mónica (meses de Julho a Setembro, 1992 a 1994).

Fig. 2 - Diurnal variation of wind direction at Comporta/Santa Mónica (July-September, 1992 at 1994). 
Este vento (do mar em direcção ao estuário), frequente durante a noite, constitui uma «brisa marinha» que, ao contrário do habitual, desaparece progressivamente durante o dia, devido à intensificação da velocidade do vento Norte na costa ocidental.

$\mathrm{O}$ aumento da velocidade do vento Norte, que se verifica muitas vezes durante o dia no litoral ocidental Português, impede a manutenção do fluxo do ar entre o oceano e o estuário, que se constitui durante a noite, quando a Nortada diminui de intensidade. O vento Norte, quando apresenta velocidades muito elevadas durante o dia, é canalizado pela depressão entre a Serra do Louro e o "morro» de Palmela e sopra sobre a Península de Tróia segundo os rumos de NNE a NNW. Este fluxo intensifica-se durante o dia e, quando regista velocidades elevadas, a sua acção não se restringe à ponta de Tróia mas penetra em toda a Península, sendo registado na estação da Comporta. Conclui-se que, durante o dia, a Nortada impede a formação da brisa do oceano e anula os ventos entre Oeste e Sul. Durante a noite, o vento de Norte é mais fraco e, devido ao desvio promovido pelo Cabo Espichel e pela Serra da Arrábida, é induzido um fluxo entre Oeste e Sul, o qual é intensificado pela diferença de temperaturas entre as águas oceânicas e as do estuário.

\section{Comparação do rumo do vento na Comporta e em Cabo Carvoeiro com o fluxo geral sobre Portugal Continental}

Para analisar o desvio do vento do quadrante Norte, durante o Verão, motivado pela Serra da Arrábida e pelo Cabo Espichel, compararam-se os registos da velocidade e dos rumos dos ventos das estações de Cabo Carvoeiro e da Comporta/Santa Mónica entre Junho e Setembro de 1992. Durante os referidos meses, o fluxo geral sobre o território do continente é de NW, N, NNW, NE e NNE em $89 \%$ dos dias, e o rumo Norte (dominante) foi observado em 32 dias (28\%) (Quadro I).

Relativamente ao fluxo geral, o rumo do vento na estação de Cabo Carvoeiro apresenta um desvio entre $0^{\circ}$ a $50^{\circ}$ em $86,9 \%$ das observações e um desvio entre $50^{\circ}$ a $180^{\circ}$ em $13,1 \%$ das observações (Quadro II). Quanto à estação de Comporta/Santa Mónica, os desvios relativamente ao fluxo geral são maiores (entre $0^{\circ}$ e $50^{\circ}$ estão $49,5 \%$ das observações e entre $50^{\circ}$ e $180^{\circ}$ estão 50,5\% das observações). Assim, podemos afirmar que, em geral, o rumo do vento na estação de Cabo Carvoeiro está mais próximo do fluxo geral do que na estação da Comporta/Santa Mónica (Quadro II).

Quanto à distribuição horária dos desvios relativamente ao fluxo geral, verifica-se que é às 0 horas que a estação da Comporta/Santa Mónica apresenta os maiores desvios (apenas 36,7\% dos registos apresentam menos de $50^{\circ}$ de desvio relativamente ao fluxo geral). Pelo contrário, Cabo Carvoeiro apresenta, às 0 horas, os desvios mais baixos relativamente ao fluxo geral (apenas 11,2\% das observações têm mais de 50 de desvio). Pelas 12 horas, a 
QUADRO I

Fluxo geral no Sul de Portugal Continental, de Junho a Setembro de 1992

TABLE I

General flux in southern Portugal (June-September 1992)

\begin{tabular}{|c|c|c|c|c|c|}
\hline & $\begin{array}{c}\text { Total } \\
\text { de } \\
\text { observações }\end{array}$ & $\begin{array}{c}\text { \% relativamente } \\
\text { ao total } \\
\text { de observações }\end{array}$ & \multirow{6}{*}{ 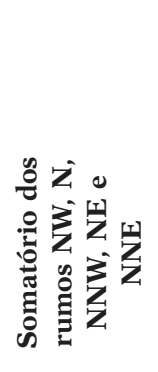 } & $\begin{array}{c}\text { Total } \\
\text { de } \\
\text { observações }\end{array}$ & $\begin{array}{c}\text { \% relativamente } \\
\text { ao total } \\
\text { de observações }\end{array}$ \\
\hline NW & 27 & 24 & & \multirow{5}{*}{101} & \multirow{5}{*}{89} \\
\hline $\mathrm{N}$ & 32 & 28 & & & \\
\hline NNW & 19 & 17 & & & \\
\hline $\mathrm{NE}$ & 7 & 6 & & & \\
\hline NNE & 16 & 14 & & & \\
\hline $\mathrm{W}$ & 3 & 3 & \multirow{5}{*}{ 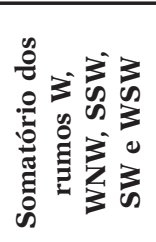 } & \multirow{5}{*}{12} & \multirow{5}{*}{11} \\
\hline WNW & 5 & 4 & & & \\
\hline SSW & 1 & 1 & & & \\
\hline SW & 2 & 2 & & & \\
\hline WSW & 1 & 1 & & & \\
\hline Total & 113 & & & 113 & \\
\hline
\end{tabular}

Dados determinados a partir dos Boletins Meteorológicos diários do I.M.

QUADRO II

Desvios em graus do rumo do vento relativamente ao fluxo geral, em Cabo Carvoeiro e Comporta (Junho a Setembro de 1992)

TABLE II

Angle between wind direction in Cabo Carvoeiro and Comporta and general flux in southern Portugal (June-September 1992)

\begin{tabular}{|c|c|c|c|c|c|c|c|c|}
\hline & \multicolumn{4}{|c|}{ Cabo Carvoeiro } & \multicolumn{4}{|c|}{ Comporta/Santa Mónica } \\
\hline & \multicolumn{2}{|c|}{$\begin{array}{c}\text { Desvios } \\
\text { de } 0^{\circ}-5^{\circ}\end{array}$} & \multicolumn{2}{|c|}{$\begin{array}{c}\text { Desvios } \\
\text { de } 50^{\circ}-180^{\circ}\end{array}$} & \multicolumn{2}{|c|}{$\begin{array}{c}\text { Desvios } \\
\text { de } 0^{\circ}-50^{\circ}\end{array}$} & \multicolumn{2}{|c|}{$\begin{array}{c}\text { Desvios } \\
\text { de } 50^{\circ}-180^{\circ}\end{array}$} \\
\hline & $\begin{array}{c}N^{\circ} \\
\text { de observações }\end{array}$ & $\%$ & $\begin{array}{c}\mathbf{N}^{\circ} \\
\text { de observações }\end{array}$ & $\%$ & $\begin{array}{c}N^{o} \\
\text { de observações }\end{array}$ & $\%$ & $\begin{array}{c}\mathrm{N} \cdot{ }^{\circ} \\
\text { de observações }\end{array}$ & $\%$ \\
\hline 0 horas & 87 & 88,8 & 11 & 11,2 & 40 & 36,7 & 69 & 63,3 \\
\hline 6 horas & 84 & 86,6 & 13 & 13,4 & 43 & 41 & 62 & 59 \\
\hline 12 horas & 85 & 85,8 & 14 & 14,2 & 64 & 61 & 41 & 39 \\
\hline 18 horas & 82 & 86,3 & 13 & 13,7 & 63 & 60 & 33 & 40 \\
\hline Total & 338 & 86,9 & 51 & 13,1 & 210 & 49,5 & 214 & 50,5 \\
\hline
\end{tabular}


estação da Comporta apresenta os desvios mais baixos relativamente ao fluxo geral (61\% das observações com menos de $50^{\circ}$ de desvio).

A comparação dos rumos do vento na estação de Cabo Carvoeiro e Comporta/Santa Mónica foi também efectuada para o Verão de 1992 (Junho a Setembro). Foram utilizados apenas os rumos do vento N a NNW em Cabo Carvoeiro, para avaliar o rumo do vento resultante, na Comporta/Santa Mónica (Quadro III). Assim, quando o vento na estação de Cabo Carvoeiro sopra de Norte (NNE a NNW), em 46,7\% das observações, o vento na estação da Comporta/Santa Mónica apresenta rumos entre Oeste e Sul (Quadro III).

Tal resultado comprova a existência de um desvio do vento do quadrante Norte, promovido pela Serra da Arrábida e pelo Cabo Espichel.

\section{A deformação das árvores e a sua relação com os rumos do vento mais frequentes na Península de Tróia e na Costa da Galé}

O desvio do vento do quadrante Norte pela Serra da Arrábida e Cabo Espichel, está, também, bem documentado na deformação das árvores. Segundo AlCOFORADo (1984 e 1994), são os ventos do quadrante Norte (N, NW) os principais responsáveis pela deformação das árvores nas serras de Sintra e na da Arrábida. É a partir de Março que os jovens rebentos das espécies arbóreas e arbustivas podem ser afectados no seu crescimento, pela acção do vento.

É precisamente a partir deste mês que os ventos do quadrante Norte se tornam dominantes e actuam na deformação das árvores e arbustos altos.

Na Península de Tróia, encontram-se deformações das árvores e/ou arbustos altos que contrariam esta dominância dos ventos do quadrante Norte. Assim, foram analisados exemplares de pinheiro-bravo (Pinus pinaster) e pinheiro-manso (Pinus pinea) próximos do litoral e, em regra situados nas cristas mais elevadas das dunas penestabilizadas e estabilizadas litorais, entre a ponta da Península de Tróia e a Lagoa de Melides. Como consequência do desvio dos ventos do quadrante Norte, durante a Primavera e Verão, a deformação mais frequente nos pinheiros situados nas cristas da duna primária da Soltróia (Península de Tróia) evidencia uma dominância do rumo do vento WSW (Fig. 3).

Na duna primária do empreendimento turístico da Soltróia, foram analisados vários indivíduos de pinheiro (Pinus pinaster), situados em crista de duna e relativamente isolados. A deformação dominante é de WSW, mas aparecem alguns indivíduos com deformação W.

Na praia da Comporta, a deformação dominante é de SW e regista-se a presença de alguns indivíduos com deformação W e WSW. Para Sul, e até à praia da Raposa, os rumos entre $\mathrm{W}$ e $\mathrm{SW}$ continuam a ser dominantes.

Assim, na praia do Pego (Carvalhal) o rumo dominante é W; no entanto, regista-se a presença de alguns indivíduos com deformação WSW e NW. A presença, rara, de alguns exemplares deformados segundo o rumo NW, na praia do Pego, indica que neste local já se fazem sentir, com alguma frequência 
Quadro III

Rumos do vento em Cabo Carvoeiro e Comporta/Santa Mónica (Junho a Setembro de 1992)

TABLE III

Wind direction in Cabo Carvoeiro and Comporta/Santa Mónica (June-September 1992)

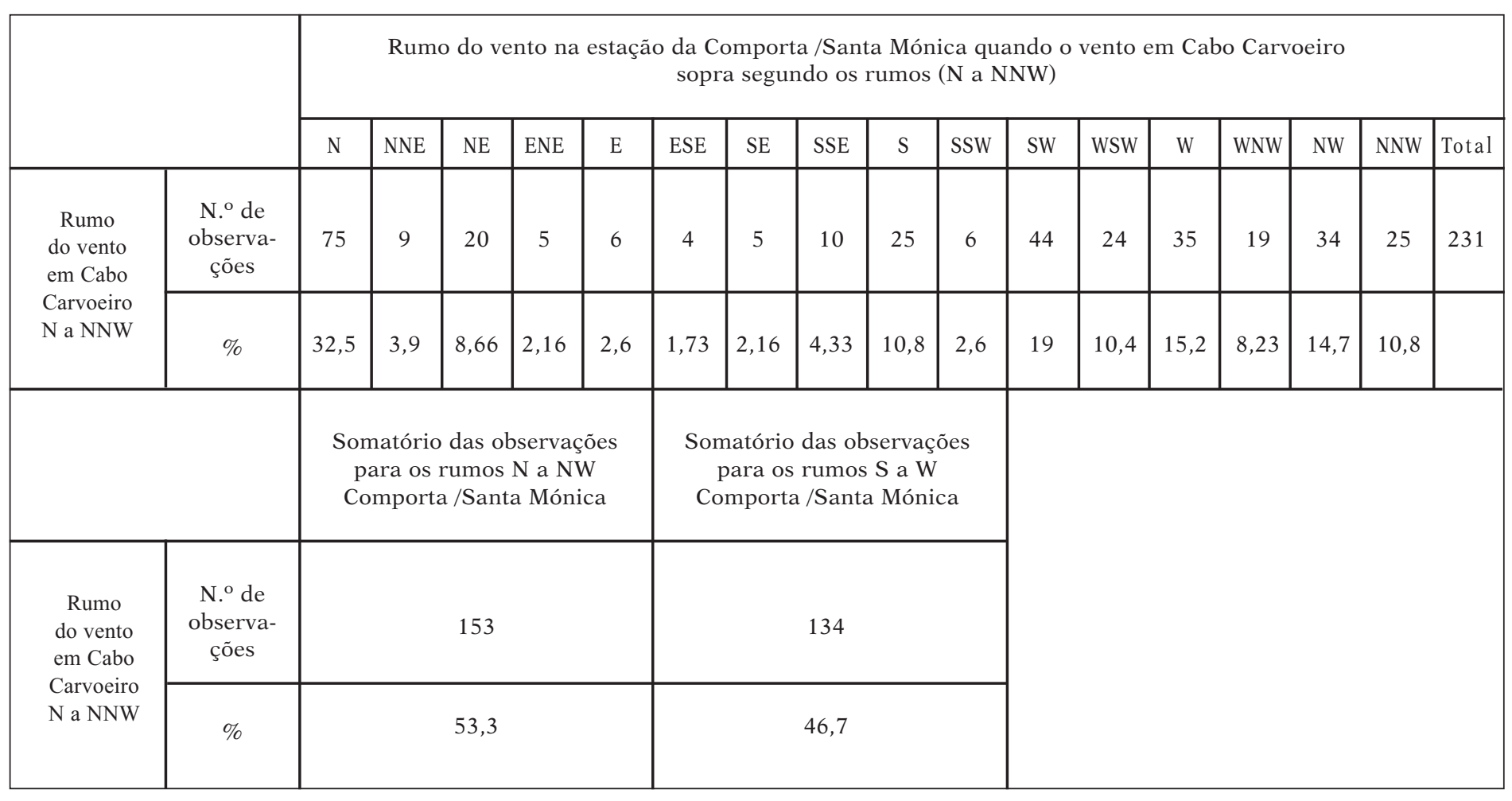




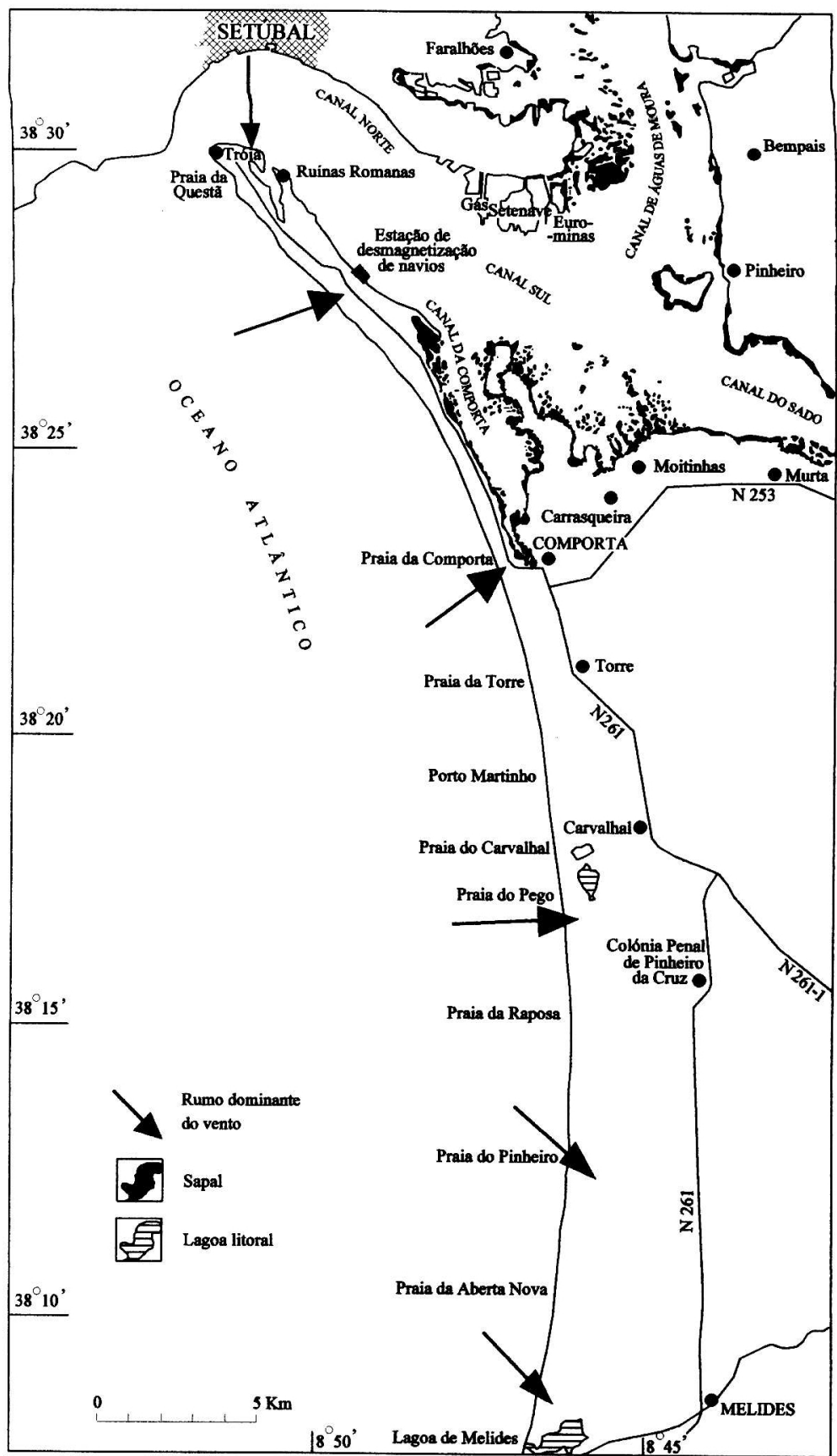

Fig. 3 - Rumos dominantes do vento no litoral entre Tróia e a Lagoa de Melides, determinados com base na deformação das árvores.

Fig. 3 - Prevailing wind direction between Tróia and Lagoa de Melides, according to wind-shaped trees. 
durante a Primavera e Verão, os ventos do quadrante Norte, mas ainda não constituem o rumo dominante.

Para Sul de Pinheiro da Cruz, os rumos do quadrante Norte são dominantes e a deformação preferencial das árvores traduz esse facto. Na praia do Pinheiro, o rumo mais frequente é NW e os rumos WNW e W estão pouco representados. Na praia da Vigia, verifica-se uma dominância do rumo $\mathrm{N}$ e os rumos NNE, NNW e W estão fracamente representados. Não foram observados pinheiros deformados (na praia da Vigia) segundo rumos de vento entre Sul e Oeste. Quanto ao extremo Norte da Península de Tróia, a deformação dominante nos indivíduos observados é de N. Os rumos NNE, NNW e W estão pouco representados. Esta dominância do rumo Norte, documentada pela deformação das árvores, traduz a canalização do vento do quadrante Norte entre a Serra do Louro e o morro de Palmela, assim como pelos terrenos baixos a Este de Palmela. Esta depressão permite a canalização e aceleração do vento do quadrante Norte, ao contrário do efeito de barreira produzido pela serra da Arrábida, e permite uma incidência frequente dos ventos do quadrante Norte na ponta da Península de Tróia, em particular quando o fluxo de Norte apresenta velocidades elevadas. Em regra, este vento de Norte não atinge o Sul da Península de Tróia, excepto quando a sua velocidade é elevada e inibe os ventos de Oeste a SW, devidos ao desvio provocado pela serra da Arrábida e pelo Cabo Espichel.

QUADRO IV

Rumo e velocidade do vento em diversos locais do estuário do Sado, no dia 15 de Julho de 1995 (situação anticiclónica com céu limpo)

TABLE IV

Wind direction and wind speed measured at different places of the Sado estuary, on July 15th 1995 (anticyclonic situation with cloudless sky)

\begin{tabular}{|l|c|c|c|c|c|}
\hline \multicolumn{1}{|c|}{ Local } & Hora & \multicolumn{2}{|c|}{$\begin{array}{c}\text { Rumo } \\
\text { do vento } \\
\text { em graus }\end{array}$} & $\begin{array}{c}\text { Rajada } \\
\text { máxima } \\
\text { em km/hora }\end{array}$ & $\begin{array}{c}\text { Velocidade } \\
\text { média } \\
\text { km/hora }\end{array}$ \\
\hline $\begin{array}{c}\text { Ponta da Península de Tróia (cais de embar- } \\
\text { que) }\end{array}$ & 16.55 & $360^{\circ}$ & $\mathrm{N}$ & 20 & 16 \\
\hline $\begin{array}{l}\text { Passadiço palafítico da Carrasqueira } \\
\text { (nivendas da Soltróia (duna primária) }\end{array}$ & 15.10 & $240^{\circ}$ & $\mathrm{WSW}$ & 15 & 12 \\
\hline $\begin{array}{c}\text { Comporta (duna primária, próximo da esta- } \\
\text { ção meteorológica da Comporta/Santa } \\
\text { Mónica) }\end{array}$ & 16.00 & $235^{\circ}$ & $\mathrm{SW}$ & 11 & 9 \\
\hline
\end{tabular}


No dia 15 de Julho de 1995 , entre as 13.10 horas e as 16.55 horas, foram efectuadas várias medições do rumo e velocidade do vento, em diversos locais da Península de Tróia. A situação sinóptica caracterizava-se pela presença de um anticiclone, localizado a Sul dos Açores e prolongando-se em crista até à Europa Ocidental. O vento era fraco de Noroeste e no Centro e Sul de Portugal Continental, o céu estava pouco nublado ou limpo. No limite norte da Península de Tróia, o vento soprava de Norte, enquanto na duna primária do empreendimento turístico da Soltróia o rumo era SW (Quadro IV). Na praia da Comporta o vento era de Oeste e a velocidade média relativamente elevada $(18 \mathrm{Km} / \mathrm{h})$.

No passadiço palafítico da Carrasqueira o vento provinha de WSW. Quase todos os locais analisados apresentavam rumos de vento entre W e SW. O vento Norte apenas soprava no limite Norte da península de Tróia, devido à, já referida, canalização e aceleração da Nortada.

\section{CONCLUSÃO}

A Serra da Arrábida e o Cabo Espichel provocam a deflecção do vento Norte, frequente durante o Verão, na costa ocidental Portuguesa. Esta deflecção nota-se na deformação das arvores e na orientação do crescimento dos arbustos da Península de Troia e da Costa da Galé, os quais apresentam rumos ente W e S para norte de Pinheiro da Cruz. O referido desvio é mais frequente durante a noite, quando a Nortada é mais fraca e é intensificada pela diferença de temperatura da água oceânica e estuarina, o que nos permite referir a existência de uma brisa nocturna. Até à realização deste estudo, este tipo de brisas não era conhecido em Portugal, pois todas as brisas do mar identificadas no litoral português são diurnas. Este facto justifica a originalidade da circulação do ar na Península de Tróia e Costa da Galé, assim como o interesse desta investigação.

A análise horária do rumo do vento, registado na estação da Comporta, evidenciaram, durante as noites de Verão, um predomínio dos rumos do quadrante Sul e, durante o dia, uma maior frequência dos ventos do quadrante Norte. Assim, verifica-se, com frequência, durante os meses do Verão, uma rotação do rumo do vento entre o dia e a noite.

Quando comparados com a estação de Cabo Carvoeiro, os rumos do vento na Comporta, durante o Verão, apresentam maiores desvios relativamente ao fluxo geral. Esses desvios são maiores durante a noite do que durante o dia, o que, correlacionado com a dominância dos ventos entre Oeste e Sul na Comporta, durante a noite, permite afirmar que estes rumos não correspondem, muitas vezes, ao rumo dominante do vento na costa ocidental. 
Este estudo conduz a várias linhas de investigação:

a) Continuação da análise das relações dos rumos e velocidade do vento entre as estações de Comporta e outras do litoral ocidental, mais próximas, nomeadamente Sines e Cabo da Roca.

b) Estudo horário da relação entre o rumo e a velocidade do vento, a temperatura e a humidade do ar.

c) Análise da circulação do ar no Estuário do Sado e na Península de Tróia, através de medições itinerantes, em diversas ocasiões.

d) Investigação da estrutura vertical do vento do oceano, que resulta da deflecção da Nortada pelo Cabo Espichel.

\section{AGRADECIMENTOS}

Este Trabalho foi financiado pelo projecto «Habitats naturais e de espécies da flora de Portugal (continente)»; projecto Life N. ${ }^{\circ}$ LIFE 94/P/A221/P/01043/LIS.

Às professoras Maria Eugénia Moreira e Maria João Alcoforado agradeço o acompanhamento do trabalho de campo e interpretação dos registos do anemógrafo.

Às professoras Denise de Brum Ferreira, Maria Helena Dias e Maria João Alcoforado, agradeço a forma cuidada com que analisaram o texto e as figuras do presente artigo.

À empresa Conlusa (Santa Mónica), agradeço a amabilidade com que me receberam nas suas instalações de S. Pedro do Estoril, facultando-me os registos da estação meteorológica que esta empresa possui na Praia da Comporta, assim como a permissão de instalação de uma nova estação meteorológica, nas dunas da Praia da Comporta.

Agradeço, também, ao Guarda Florestal Armandino Severino, a disponibilidade que demonstrou para a manutenção dos aparelhos da estação e recolha da informação.

\section{BIBLIOGRAFIA}

Alcoforado, M. J. (1984) - Os ventos dominantes em torno da Serra de Sintra. Relatório 20, L.A.G.F., C.E.G., Lisboa, 72 p.

Alcoforado, M. J. (1992) - O clima da região de Lisboa. Memórias do Centro de Estudos Geográficos, 7, Lisboa, $84 \mathrm{p}$.

Alcoforado, M. J. (1994) - A vegetação como indicador dos ventos dominantes. Anais do Instituto Superior de Agronomia, Vol. XLIV (2): 667-689.

Barros, N. e Borrego, C. (1994) - Influence of Coastal Breezes in the Atmospheric Dispersion Over Lisbon Region. Litoral, 94: 26-29. 
Ferreira, D. Brum (1984) - Le Système Climatique de l'upwelling ouest Ibérique. Relatório do Centro de Estudos Geográficos, n. ${ }^{\circ} 19$, Lisboa, 89 p.

Daveau, S. et al. (1985) - Dois mapas climáticos de Portugal. Nevoeiro e nebulosidade. Contrastes térmicos. Memórias do Centro de Estudos Geográficos, 7, Lisboa, 84 p.

Carvalho, J. R. e Barceló, J. P. (1966) - Agitação marítima na costa W de Portugal metropolitano. Memórias do L.N.E.C., n. ${ }^{\circ} 290,34$ p. 